\title{
The measurement of perennial ryegrass persistence
}

\author{
M.B. DODD ${ }^{1 *}$, D.F. CHAPMAN ${ }^{2}$, C.I. LUDEMANN ${ }^{1}$, W. GRIFFITHS ${ }^{1}$, K.N. TOZER ${ }^{3}$ and L. DONNELLY ${ }^{4}$ \\ ${ }^{1}$ AgResearch Ltd, Grasslands Research Centre, Private Bag 11008, Palmerson North 4410, New Zealand \\ ${ }^{2}$ DairyNZ, PO Box 85066, Lincoln University, Lincoln 7647, New Zealand \\ ${ }^{3}$ DairyNZ, Private Bag 3221, Hamilton 3240, New Zealand \\ ${ }^{4}$ AgResearch Ruakura, Private Bag 3123, Hamilton 3240, New Zealand \\ ${ }^{5}$ SeedForce Ltd, Christchurch, New Zealand \\ mike.dodd@agresearch.co.nz
}

\begin{abstract}
Poor persistence in perennial ryegrass has been identified as a major limitation to pasture productivity, particularly in the upper North Island. Persistence can best be defined as the continuity of forage yield relative to a cultivar's potential. Though there is limited evidence of differences in persistence between cultivars, there is interest in including persistence in the DairyNZ Forage Value Index. This requires an agronomically robust metric of persistence, measured over a suitable time frame and connected to economic value. Five candidates are evaluated: plant populations, tiller populations, basal cover, ground score and annual dry matter yield. Scarcity of long-term data is a major limitation to development of performance values for persistence, and must be addressed. The four abundance-based measures also lack a clear connection to economic values, from the limited data available. A persistence metric is proposed, that relates mediumterm dry matter yield to short-term dry matter yield, for which perennial ryegrass functional type and cultivar differences are demonstrated.
\end{abstract}

Keywords: basal cover, dry matter yield, Forage Value index, ground score, tillers

\section{Introduction}

Poor persistence in perennial ryegrass has been identified as a major limitation to pasture productivity, particularly in the upper North Island. The reasons for this are not known but likely involve a combination of factors such as climate, soil, pest pressure and grazing management. Some farmers believe that modern genotypes are less persistent than older ecotype-based perennial ryegrasses (Tozer et al. 2011). While there is now good evidence to indicate that there is no inherent difference between 'new' and 'old' ryegrass cultivars in their ability to survive in pastures grazed by dairy cows (Lee et al. 2017), differences have been reported among cultivars in persistence of dry matter (DM) yield (Chapman et al. 2015), and ability to survive in physically stressful environments (Thom et al. 1998).

It has been proposed that persistence be included as a trait in the Forage Value Index (FVI, Chapman et al. 2017) to enable farmers to make better choices between cultivars and to give plant breeders direction for germplasm selection. A fundamental requirement for this development is the identification of a suitable measure of cultivar performance values for persistence. This is challenging since, by definition, persistence is a long-term outcome which is expensive to measure directly. An additional challenge is to define what it is about pastures that should persist, or conversely what is not persisting. Operationally, this can be either an entity (the grass itself) or a characteristic of the entity (e.g. a yield or forage quality trait, Parsons et al. 2011).

Working definitions of persistence vary in the agronomic literature. While they have a common focus on the species sown (rather than the whole sward), they diverge on the matter of persistence of the entity (e.g. tiller and plant populations, Camlin \& Stewart 1978) versus persistence of the trait (e.g. yield, Chapman et al. 2015).

To develop a robust metric for persistence that can be incorporated into the FVI, the following are necessary:

a. Define an ecologically robust and agronomically relevant measure of persistence that can reliably differentiate between cultivars (or at least functional types such as ploidy and heading date). The metric should be readily measurable on large numbers of plants and be heritable;

b. Define a relevant time frame;

c. Identify existing long-term datasets, or collect such datasets, that include the selected measure across a range of germplasm;

d. Demonstrate a clear link between the persistence measure and the performance value of the germplasm that can then be assigned an economic value.

The purpose of this paper is to use these criteria to explore the utility of some potential candidates for the measurement of persistence, and to propose a suitable metric.

\section{Candidate measures of persistence}

This section considers the advantages and disadvantages of four measures of abundance (plant

*Research was conducted during a secondment to DairyNZ 


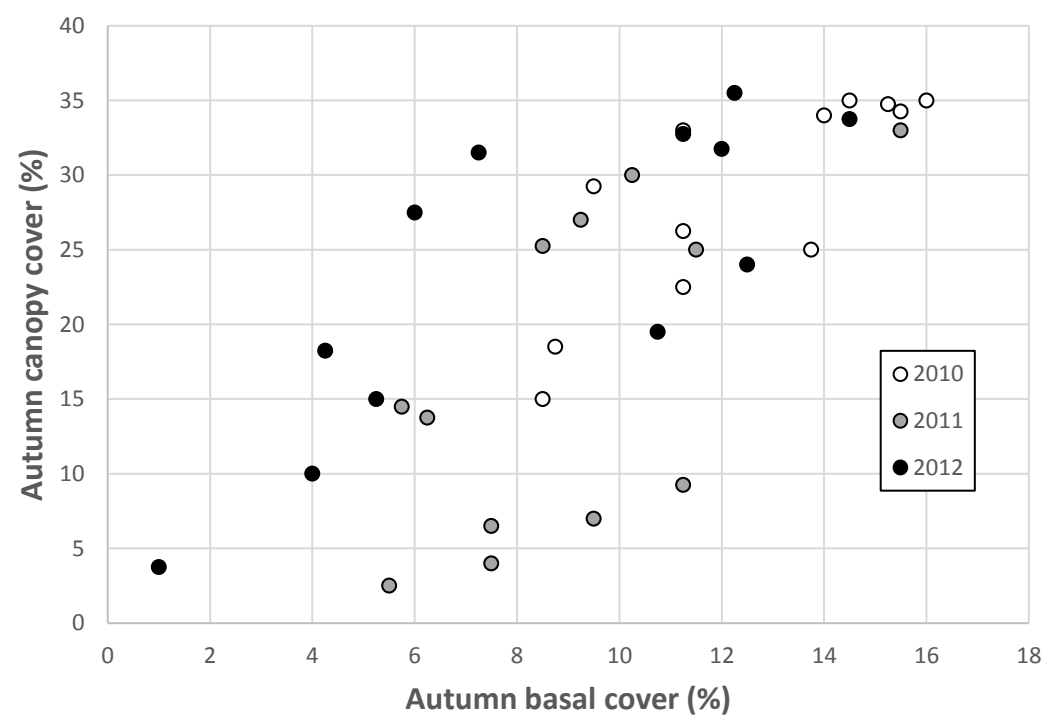

Figure 1 Basal and canopy area of perennial ryegrass, in small plot mixed species swards in the Waikato study of Tozer et al. (2017). Open circles = April 2010, Grey circles = April 2011, Filled circles $=$ April 2011.

populations, tiller populations, basal area/cover and ground score) and one measure of performance (DM yield), as potential candidates for development of a persistence metric.

\section{Plant populations}

While relatively simple to measure in the early stages of sward establishment, measurement of individual plants becomes problematic beyond 2 years, due to the clonal nature of grass plants undergoing continual tillering and fragmentation (Brock et al. 1996). It is difficult to delineate clusters of tillers as belonging to discrete plants in mature swards. For this practical reason alone, plant population variables are a poor choice for measuring persistence. In addition, simple population counts do not account for variation in plant size, which has a substantial effect on individual plant longevity (Lee et al. 2017).

\section{Tiller populations}

The tiller is the fundamental unit of vegetative growth in grasses and thus is probably the most agronomically robust measure of persistence (Matthew et al. 2000). However, tiller development has considerable morphological plasticity in grasses, mediated through the inverse relationship between tiller density and size (Gastal \& Lemaire 2015). This relationship allows swards to attain maximal leaf area (within prevailing environmental and genetic limits) by multiple combinations of tiller density and size (Matthew et al. 1996). Thus, while lack of persistence will usually be associated with a long-term decline in tiller numbers; short-term declines over a non-critical range in tiller densities (4000-8000 tillers $\left./ \mathrm{m}^{2}\right)$ may not necessarily reflect persistence failure (Matthew et al. 2013).

A key advantage of using tiller variables to measure persistence is the ability for plant breeders to select for this trait. While cultivar marketing material often includes qualitative information on relative tiller density, it appears to have been of low priority in previous cultivar development, perhaps because the evidence on its contribution to persistence is equivocal (Lee et al. 2012). However, as with plant populations, tiller populations are timeconsuming to measure accurately in the field.

\section{Basal cover}

Basal cover is a measure of the abundance of plants according to the coverage of live tissue at ground level, usually expressed as a proportion or percentage of the total area surveyed. The precise details of measurement vary between studies, such as point intersect (Rhodes \& Collins 1993) or presence within defined horizontal grid cells (Virgona \& Bowcher 2000). As with plant and tiller populations, measurement is necessarily manual and time consuming in the field. No published examples of the use of basal cover for comparisons of cultivar persistence are obvious, although Tozer et al. (2017) assessed both basal and canopy cover of ryegrass within a range of pasture species mixes sown in small plots. Their data from 3 consecutive years indicate only a moderate positive correlation between the two $(r=0.73$, Figure 1). Canopy cover is likely to be strongly correlated with visual ground cover estimates, the fourth abundance measure considered here.

\section{Ground score}

Camlin \& Stewart (1978) used a 0-9 scale visual score of relative ground cover during winter to assess persistence of ryegrass cultivars in the second year after sowing, demonstrating that this was highly correlated to herbage yield in the fourth year. This measurement is now referred to as ground score (GS) and changes in GS over time have been used in the 
Irish equivalent of the FVI as the basis for assessing persistence (Pasture Profit Index, PPI, O'Donovan et al. 2016). The economic value for persistence in the PPI is derived from the relationship between interannual changes in DM yield and GS (1683 kg DM/unit GS) as reported by Cashman et al. (2014).

New Zealand National Forage Variety Trial (NFVT) protocols originally included point analysis measurements after 3 years as a standard assessment of persistence, but in 2013 this changed to using visual ground score in winter each year (rating on a 1-9 scale at approximately 2 weeks post-grazing, where a ' 1 ' corresponds to $10 \%$ or less sown ryegrass presence and a ' 9 ' corresponds to $90 \%$ or greater sown ryegrass presence, M. McLeod pers. comm.). This shift was made in recognition of a poor relationship between the initial method and observations of persistence in other trials or on-farm (Kerr et al. 2012). Adoption of GS reflects its practical utility, scalability from small plot to paddock, and the inherent integration of plasticity in the main yield components (tiller or plant number and size).

\section{Dry matter yield}

Measurement of dry matter yield over time represents the most conclusive assessment of persistence, since dry matter yield is the primary driver of productivity (Parsons et al. 2011; Chapman et al. 2015). However, yield over time is highly dependent upon climatic conditions, and thus it is necessary to define persistence as the continuity of potential dry matter yield. This presents the challenge of defining what potential yield is. There are three possibilities: a) yield measured in the first few years of establishment, b) maximum yield of a range of genotypes of the species in each year of measurement, and c) yield estimated by a physiologically-based model simulating yield under a given weather pattern. Using yield in a given year or sequence of years after establishment as the potential yield allows for relativity to the potential of that genotype with likely minimal impact of weed ingress. However, it is problematic in that the difference between the potential yield benchmark post-establishment and the yield in later years could be interpreted as poor persistence, but actually be the result of other factors such as climatic conditions or increases in pest load (Farquhar et al. 2017). Using the maximum yield expressed by a range of genotypes during a period of measurement could be confounded by genotype inclusion, that is, it assumes that the genotype best-adapted to those climatic conditions is being used and measured. The potential issue in using a modelling approach is that most models are parameterised to field measurements of average yield rather than maximum yield. However, an approach that uses sensitivity analysis of variation in plant traits may be useful in quantifying potential yield as a benchmark (e.g. White \& Snow 2012).

The best option appears to be to use yield measured on an individual cultivar during an establishment period of suitable length to minimise the effects of seasonal climate and weed ingress, this also has the advantage of expressing persistence in the context of the potential of that cultivar, independent of the performance of the cultivar relative to other cultivars.

\section{Time scales and data limitations}

While there is no agreed definition of the appropriate time scale for the assessment of persistence in perennial pastures, farmer surveys give some indication of a "user expectation" of the longevity of perennial pastures. Daly et al. (1999) surveyed sheep and beef farmers across New Zealand and reported that $45 \%$ of respondents expected pastures to last between 11 and 20 years, while $31 \%$ expected pastures to last longer than 21 years. Rijswijk \& Brazendale (2016) surveyed dairy farmers in the upper North Island and noted an average expectation of 11 years before pasture renewal was necessary, with just over half the respondents selecting a 6 to 10 -year time frame. Ideal pasture renewal time frames are strongly influenced by economic considerations (Malcolm et al. 2014), who highlight the dependence on the annuity derived. The PPI uses 12 years as a benchmark, citing the balance between persistence and genetic gain, O'Donovan et al. 2016).

Current performance values in the FVI are calculated based on 3-year field assessments of DM yield in the NFVT. Three years is generally considered to be "short-term" for perennial pastures, and hence there is currently no systematic data collection incorporating a range of genotypes over time scales more relevant to the question of persistence.

Indeed, in New Zealand there are few agronomic field assessments of forage grasses longer than 3 years. Most studies of greater than 3 years have compared different grass species (e.g. Barker et al. 1993), and only four have incorporated comparisons of multiple genotypes/cultivars within species (Allan \& Keoghan 1994; Chapman et al. 2015; Black \& Moir 2015; Lee et al. 2017). Except for Allan \& Keoghan (1994), who used a plant survival score, these studies have used DM yield and/or botanical composition as the main measure of persistence. Lee et al. (2017) observed no difference in the persistence of four perennial ryegrass cultivars under substantial climate and pest stress in the Waikato, based on DM yields, and this is the only study to have reported long-term measurements of tiller density (over 6 years). That data set shows 
a similar long-term decline for all four perennial ryegrass cultivars.

Only two studies incorporating long-term ground score assessments appear to be available. The study of Chapman et al. (2015) included unpublished persistence scores conducted in May of Years 2 and 3, July of Year 4 and September of Year 5. These data are explored further in the following section. The second data set comes from an unpublished field evaluation of 18 perennial ryegrass cultivars conducted from 2006-2014 at a dryland Canterbury site $(733 \mathrm{~mm}$ mean annual rainfall). The cultivars were sown in spring 2006 as pure swards in small plots $(1.5 \times 8 \mathrm{~m})$ on a Wakanui silt loam, with each cultivar replicated four times in a randomised complete block design (L. Donnelly unpubl. data). Plots were grazed by beef cattle and received the equivalent of $20 \mathrm{~kg} \mathrm{~N} / \mathrm{ha}$ as fertiliser after every second grazing. Herbage accumulation was assessed by capacitance probe measurements pre- and post-grazing. Visual GS measurements using the NFVT method (NZPBRA unpubl. report) were conducted in February of years 6,8 and 9. However, an analysis of variance found no significant differences between cultivars or heading date groups in the linear trend of ground scores over time.

It seems clear that there are insufficient data currently available to a) support the choice of one candidate measure over another, or b) constitute a robust cultivar comparison for discriminating on persistence. The design and implementation of relevant data collection over periods much greater than 3 years is therefore a vital step in resolving this situation, and generating performance values for persistence in the FVI.

\section{Persistence measure and performance value}

One of the key issues with all four abundance-based measures of persistence (plant population, tiller population, basal area and GS) at this stage is that, in contrast to the case for GS within the PPI (O'Donovan et al. 2016), no clear connection exists between any of them and a performance value for persistence in grazed pastures in New Zealand. A distinct advantage of the type of indirect measures discussed here is that they could be deployed early in the life of a pasture to predict long-term performance (the 'ex-ante' approach), avoiding the 'drag' on genetic progress imposed by waiting for $6+$ years for information ('ex-post' approach). Thus, further investigation of connections to performance values is warranted.

If successful, two important linkages to FVI methodology could be established: 1) the connection between the persistence metric and the on-farm decision to ryegrass, which will be reflected in the annualised cost of pasture renovation; and 2) the connection between the persistence metric and forage yield over time, which will be reflected in the opportunity cost of foregone DM yield. The first of these is likely to be highly subjective, based on an individual's threshold for performance, though this may still be amenable to objective economic analysis (Malcolm et al. 2014). The second linkage suffers from a dearth of data from field studies that include long-term concurrent measures of species abundance and forage yield for multiple genotypes.

The trial described by Chapman et al. (2015) comes closest to meeting these requirements. Including a visual measurement of ground cover using a 1-10 scale (similar to the GS technique) in May 2008 (beginning Year 3) and September 2010 (mid-Year 5). Regression of these scores against measured herbage yield in the subsequent July-June growing seasons shows a weak positive relationship (Figure 2). The slope of the two regression equations is remarkably similar at $\sim 700 \mathrm{~kg}$ annual DM yield for every unit score even after taking account of the different seasonal timing of the ground cover scores, and the difference in the interval between scoring and the subsequent total annual DM yield assessment periods. However, it must be recognised that this value is highly site and season specific and the variance is high, likely driven by tiller size-density compensation (Matthew et al. 2010, 2013). Figure 2 indicates a similar yield is achieved by cultivars scoring up to 5 GS units apart. A more robust approach uses the relationship between the inter-annual change in DM yield associated with an inter-annual change in GS (Cashman et al. 2014).

The unpublished data of Donnelly noted above, included both GS and DM yield assessments for two periods over the 8-year study: Year 6-7 and Year 7-8. A correlation analysis of the inter-annual change in DM production versus inter-annual change in GS (after Cashman et al. 2014) of the 18 cultivars showed no clear relationship.

The poor relationship between abundance measures and yield performance, albeit based on limited data, emphasises that the criteria for an indirect persistence metric with any utility for the FVI are far from being met. Until this situation is resolved, an alternative approach is proposed, which uses the more reliable variable of DM yield data to develop a scaling factor to modify the yield performance values currently used within the FVI.

\section{A proposed persistence scalar}

The persistence scaling factor proposed here is based on herbage yield measurement of the cultivar of interest, incorporating the following assumptions:

1. Herbage DM yield in the first few years following establishment best represents the yield potential of a particular cultivar. Three years is considered 
a minimum period for setting this benchmark, to account for climatic variation between years.

2. The DM yield of a cultivar over the longterm $(>3$ years) relative to DM yield in the shortterm $(<3$ years $)$ best represents persistence from a farm systems perspective, can be measured in the field, and readily translates into economic value. Three years beyond the initial benchmark period is considered a minimum for assessing long-term yield, again to adequately account for the impact of inter-annual climatic variation.

3. Data used should exclude the contribution to yield of other species/cultivars within the measured area (e.g. white clover, unsown species.)

The persistence scalar

is expressed as the ratio of long-term to short-term herbage DM yield by the following equation:

Persistence scalar $(\operatorname{Ps}[4,5,6])=$ Mean annual DM yield [Years 1,2,3,4,5,6]/ Mean annual DM yield [Years 1,2,3] (Equation 1, Table 1)

The calculation can be flexible to allow for other periods of long-term data collection, e.g. the mean of later years $(\operatorname{Ps}[6,7,8])$ or non-consecutive years ( $\mathrm{Ps}[5,7,9])$ as long as this is expressed in the notation as indicated (Table 2).

A re-analysis of two recent perennial ryegrass cultivar field comparisons with this equation is presented in Tables 1 and 2. The first is from the Lee et al. (2017) study in the Waikato, which indicates that the two mid-season heading diploid cultivars 'Nui' and 'Commando' were significantly less persistent than the lateseason heading cultivars 'Alto' and 'Halo' in that

Dip $=$ diploid; Tet $=$ tetraploid

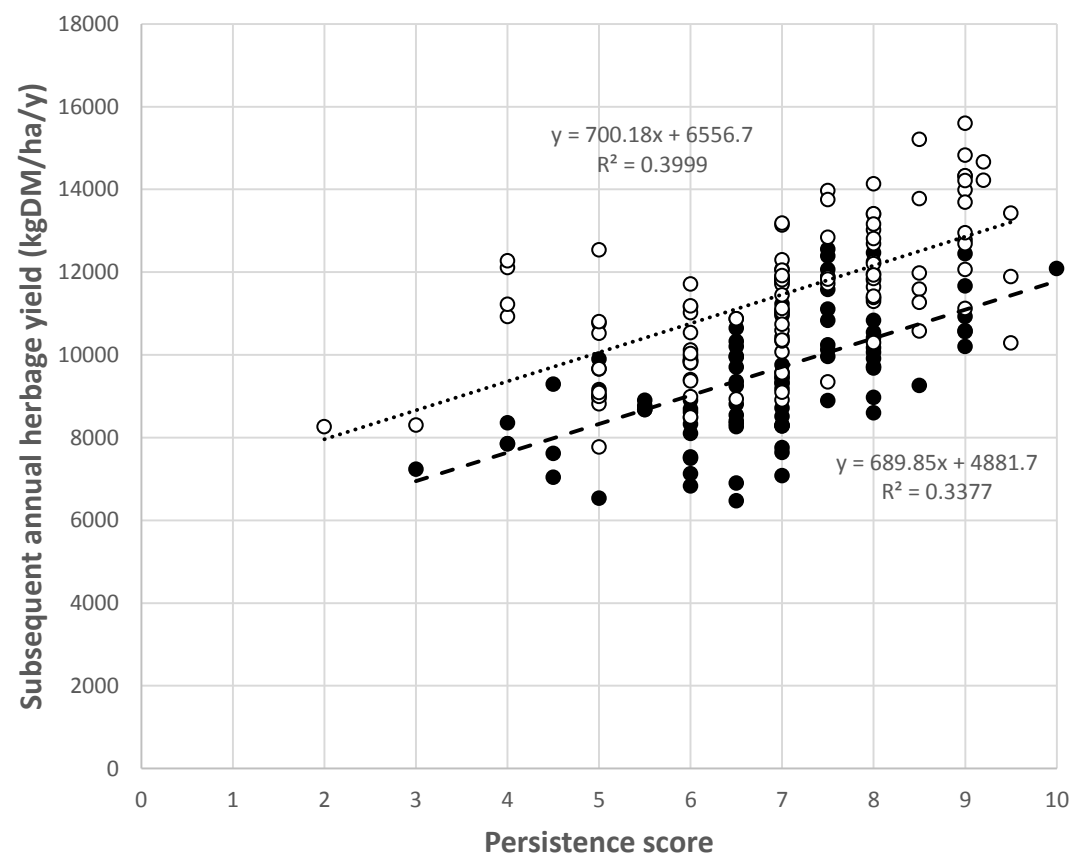

Figure 2 Regression of annual herbage yield versus persistence score for 25 cultivar/ endophyte combinations each replicated in four plots, from the study of Chapman et al. (2015). Filled circles, dashed line = persistence score in May 2008 (Year 3 atter sowing) versus total annual DM yield for July 2008-June 2009; open circles, dotted line = persistence score in September 2010 (Year 5 after sowing) and total annual DM yield for July 2011-June 2012.

environment $(\mathrm{P}<0.05$, Table 1). The second is from the Hawke's Bay data of Chapman et al. (2015), where the long-term yield data were from Years 7, 8, 10 and 11. The results showed both a significant difference between cultivars grouped by heading date and ploidy $(\mathrm{P}<0.001)$, as well as a significant cultivar effect within those groups $(\mathrm{P}<0.05)$. The very late tetraploid cultivars were significantly less persistent than the two diploid groups, with a large range within those groups (Table 2).

The proposed metric necessitates the collection of longer-term data from field evaluation trials than is

Table 1 Mean persistence scalar values (Ps[4,5,6] as per Equation 1) of four perennial ryegrass cultivars in the field experiment of Lee et al. (2017). Values followed by different letters are significantly different at $\mathrm{P}<0.05$.

\begin{tabular}{lccc}
\hline Cultivar (endophyte) & Ploidy & Heading & Ps[4,5,6] value (SED) \\
\hline 'Alto' (AR37) & Dip & Late & $0.866 \mathrm{a}(0.021)$ \\
'Commando' (AR37) & Dip & Mid & $0.797 \mathrm{~b}(0.013)$ \\
'Halo' (AR37) & Tet & Very late & $0.854 \mathrm{a}(0.023)$ \\
'Nui' (SE) & Dip & Mid & $0.800 \mathrm{~b}(0.006)$ \\
\hline
\end{tabular}


currently the case. This potentially slows down the rate of development of new cultivars, although if there is sufficient demand for the improvement of persistence in future cultivars, this cannot be avoided since collection of long-term data is axiomatic for the trait. It is anticipated that the collection of such data may in future lend itself to development of short-term proxies with a higher level of confidence than is currently the case (viz. Chapman et al. 2015). Hence, measurements of parameters other than DM yield (particularly ground score) should also be included in such long-term trials. Ideally, genomic analysis of survivor plants would be conducted in parallel. A programme of this type may help elicit robust phenotypic or genetic indicators of long-term performance that will expedite trialling and genetic progress in the future.

\section{Conclusions}

There are very few multi-genotype comparative data sets of sufficient longevity relative to farmer expectations around persistence (6-10 years). The most agronomically robust measures (plant and tiller populations, basal cover) are highly variable in space and time and difficult and/or expensive to measure. For the simplest measure (ground score), sufficient longterm data and a verifiable connection to a performance value based on dry matter production are both lacking. Long-term DM yield is the easiest variable to translate to performance values, but the paucity of long-term studies means that clear conclusions regarding genetic differences among current perennial ryegrass cultivars in dairy pastures cannot yet be drawn. Trials of at least 6 years, that include yield, abundance and genomic data, should be established at representative locations to collect cultivar persistence performance values for the FVI.

\section{ACKNOWLEDGEMENTS}

This research was funded by DairyNZ Inc. via investment schedule RD1414. Thanks to the DairyNZ technical team for raw data from Lee et al. (2017) and to Barbara Dow (DairyNZ) for statistical analyses of unpublished data.

\section{REFERENCES}

Allan, B.E.; Keoghan, J.M. 1994. More persistent legumes and grasses for oversown hill country. Proceedings of the New Zealand Grassland Association 56: 143-147.

Barker, D.J.; Lancashire, J.A.; Moloney, S.J.; Dymock, N.; Stevens, D.R.; Turner, J.D.; Scott, D.; Archie, W.J. 1993. Introduction, production and persistence of five grass species in dry hill country 8 . Summary and conclusions. New Zealand Journal of Agricultural Research 36: 61-66.

Black, A.D.; Moir, J.L. 2015. Dry matter and sheep production of four dryland tall fescue-clover pastures 4-6 years after establishment. Journal of New Zealand Grasslands 77: 117-122.

Brock, J.; Hume, D.; Fletcher, R. 1996. Seasonal variation in the morphology of perennial ryegrass (Lolium perenne) and cocksfoot (Dactylis glomerata) plants and populations in pastures under intensive sheep grazing. The Journal of Agricultural Science 126: 37-51.

Camlin, M.S.; Stewart, R.H. 1978. The assessment of persistence and its application to the evaluation of mid-season and late perennial ryegrass cultivars. Grass and Forage Science 33: 275-282.

Cashman, P.; O'Donovan, M.; Gilliland, T.; McEvoy, M. 2014. Quantifying ground score change on perennial ryegrass swards exposed to different grazing regimes. p. $89 \mathrm{In}$ : Proceedings of the 40th Annual Meeting of the Irish Grassland and Animal Production Association, (Ed.). Diskin, M. Irish Grassland and Animal Production Association. Athenry, Co Galway, Ireland.

Chapman, D.F.; Bryant, J.R.; Olayemi, M.E.; Edwards, G.R.; Thorrold, B.S.; McMillan, W.H.; Kerr, G.A.; Judson, G.; Cookson, T.; Moorhead, A.; Norriss, M. 2017. An economically based evaluation index for perennial and short-term ryegrasses in New Zealand

Table 2 Persistence scores (as per Equation 1) of three perennial ryegrass cultivar groups in the field study of Chapman et al. (2015) in the Hawke's Bay. Values followed by different letters are significantly different at $P<0.05$.

\begin{tabular}{lccc}
\hline Heading date group & Ploidy & $\begin{array}{c}\text { Ps[7,8,10,11] value } \\
\text { Mean SED }=\mathbf{0 . 0 0 9}\end{array}$ & $\begin{array}{c}\text { Cultivar range } \\
\text { (Number of cultivars) }\end{array}$ \\
\hline Mid & Dip & $0.918 \mathrm{a}$ & $0.887-0.941(11)$ \\
Late & Dip & $0.921 \mathrm{a}$ & $0.897-0.944(4)$ \\
Very late & Tet & $0.878 \mathrm{~b}$ & $0.870-0.889(3)$ \\
Group effect & & $\mathrm{P}<0.01$ & \\
Cultivar within group effect & & $\mathrm{P}<0.05$ & \\
\hline
\end{tabular}

Dip=diploid; Tet=tetraploid 
dairy farm systems. Grass and Forage Science 72: $1-21$.

Chapman, D.F.; Muir, P.D.; Faville, M.J. 2015. Persistence of dry matter yield among New Zealand perennial ryegrass (Lolium perenne L.) cultivars: insights from a long-term data set. Proceedings of the New Zealand Grassland Association 77: 177-184.

Daly, M.J.; Fraser, T.; Perkins, A.; Moffat, C.M. 1999. Farmer perceptions of reasons for perennial pasture persistence and the relationship of these with management practice, species composition and soil fertility. Proceedings of the New Zealand Grassland Association 61: 9-15.

Farquhar, M.R.; Winefield, C.S.; Eady, C.C. 2017. Dry matter yield and the prevalence of barley yellow dwarf and ryegrass mosaic viruses in old and young perennial ryegrass. Journal of New Zealand Grasslands 79: 165-171.

Gastal, F.; Lemaire, G. 2015. Defoliation, shoot plasticity, sward structure and herbage utilization in pasture: review of the underlying ecophysiological processes. Agriculture 5: 1146-1171.

Kerr, G.A.; Chapman, D.F.; Thom, E.R.; Matthew, C.; Van der Linden, A.; Baird, D.B.; Johnston, E.; Corkran, J.R. 2012. Evaluating perennial ryegrass cultivars: improved testing. Proceedings of the New Zealand Grassland Association 74: 127-136.

Lee, J.M.; Matthew, C.; Thom, E.R.; Chapman, D.F. 2012. Perennial ryegrass breeding in New Zealand: a dairy industry perspective. Crop and Pasture Science 63: 107-127.

Lee, J.M.; Thom, E.R.; Wynn, K.; Waugh, D.; Rossi, L.; Chapman, D.F. 2017. High perennial ryegrass seeding rates reduce plant size and survival during the first year after sowing: does this have implications for pasture sward persistence? Grass and Forage Science 72: 382-400.

Malcolm, B.; Smith, K.F.; Jacobs, J.L. 2014. Perennial pasture persistence: the economic perspective. Crop and Pasture Science 65: 713-720.

Matthew, C.; Agnusdei, M.G.; Assuero, S.G.; Sbrissia, A.F.; Scheneiter, O.; Da Silva, S.C. 2013. State of knowledge in tiller dynamics. Proceedings of the 22nd International Grassland Congress: 1041-1044. https://www.internationalgrasslands.org/files/igc/ publications/2013/proceedings-22nd-igc.pdf

Matthew, C.; Assuero, S.G.; Black, C.K.; SackvilleHamilton, N.R. 2000. Tiller dynamics of grazed swards. pp. 109-133. In: Grassland ecophysiology and ecology. (Eds.) Lemaire, G.; Hodgson, J.; Moraes, A.; Carvalho, P.C.F.; Nabinger, C. CABI Publishing, Wallingford, UK.

Matthew, C.; Hernandez-Garay, A.; Hodgson, J. 1996. Making sense of the link between tiller density and pasture production. Proceedings of the New Zealand Grassland Association 57: 83-87.

O’Donovan, M.; McHugh, N.; McEvoy, M.; Grogan, D.; Shalloo, L. 2016. Combining seasonal yield, silage dry matter yield, quality and persistency in an economic index to assist perennial ryegrass variety selection. Journal of Agricultural Science 155: 556568.

Parsons, A.J.; Edwards, G.R.; Newton, P.C.D.; Chapman, D.F.; Caradus, J.R.; Rasmussen, S.; Rowarth, J.S. 2011. Past lessons and future prospects: plant breeding for yield and persistence in cooltemperate pastures. Grass and Forage Science 66: 153-172.

Rhodes, I.; Collins, R.P. 1993. Canopy structure. pp. 139-156. In: Sward measurement Handbook. Eds. Davies, A.; Baker, R.D.; Grant, S.A.; Laidlaw, A.S. Sward measurement handbook. 2nd Edition. British Grassland Society, Reading, UK.

Rijswijk, K.; Brazendale, R. 2016. Pasture renewal practices, experiences, and attitudes. Journal of New Zealand Grasslands 78: 51-56.

Thom, E.R.; Waugh, C.D.; McCabe, R.J. 1998. Growth and persistence of perennial and hybrid ryegrasses when grazed by dairy cows in the central Waikato region of New Zealand. New Zealand Journal of Agricultural Research 41: 477-486.

Tozer, K.N.; Cameron, C.A.; Thom, E.R. 2011. Pasture persistence: farmer observations and field measurements. Pasture Persistence. Grassland Research and Practice Series 15: 25-30.

Tozer, K.N.; Minneé, E.M.K.; Greenfield, R.M.; Cameron, C.A. 2017. Effects of pasture base and species mix complexity on persistence and weed ingress in summer-dry dairy pastures. Crop and Pasture Science 68: 561-573.

Virgona, J.M.; Bowcher, A. 2000. Effects of grazing interval on basal cover of four perennial grasses in a summer-dry environment. Australian Journal of Experimental Agriculture 40: 299-311.

White, T.A.; Snow, V.O. 2012. A modelling analysis to identify plant traits for enhanced water-use efficiency of pasture. Crop and Pasture Science 63: 63-76. 
